Desenhos de Pesquisa

\title{
LUGARES DA EXPERIÊNCIA NA CENA PERFORMATIVA RECENTE: UMA PROBLEMATIZAÇÃO ACERCA DO ESPECTADOR E SEU EXERCÍCIO CRÍTICO DE LEITURA/PRODUÇÃO
}

SEATS OF EXPERIENCE IN RECENT PERFORMATIVE SCENE: A QUESTIONING ABOUT THE SPECTATOR AND HIS CRITICAL EXERCISE OF READING/PRODUCTION

LUGARES DE EXPERIENCIA EN LA ESCENA PERFORMATIVA RECIENTE: CUESTIONAMIENTOS SOBRE EL ESPECTADOR Y SU EJERCICIO CRÍTICO DE LA LECTURA/PRODUCCIÓN

\section{Cecília Lauritzen Jácome Campos}

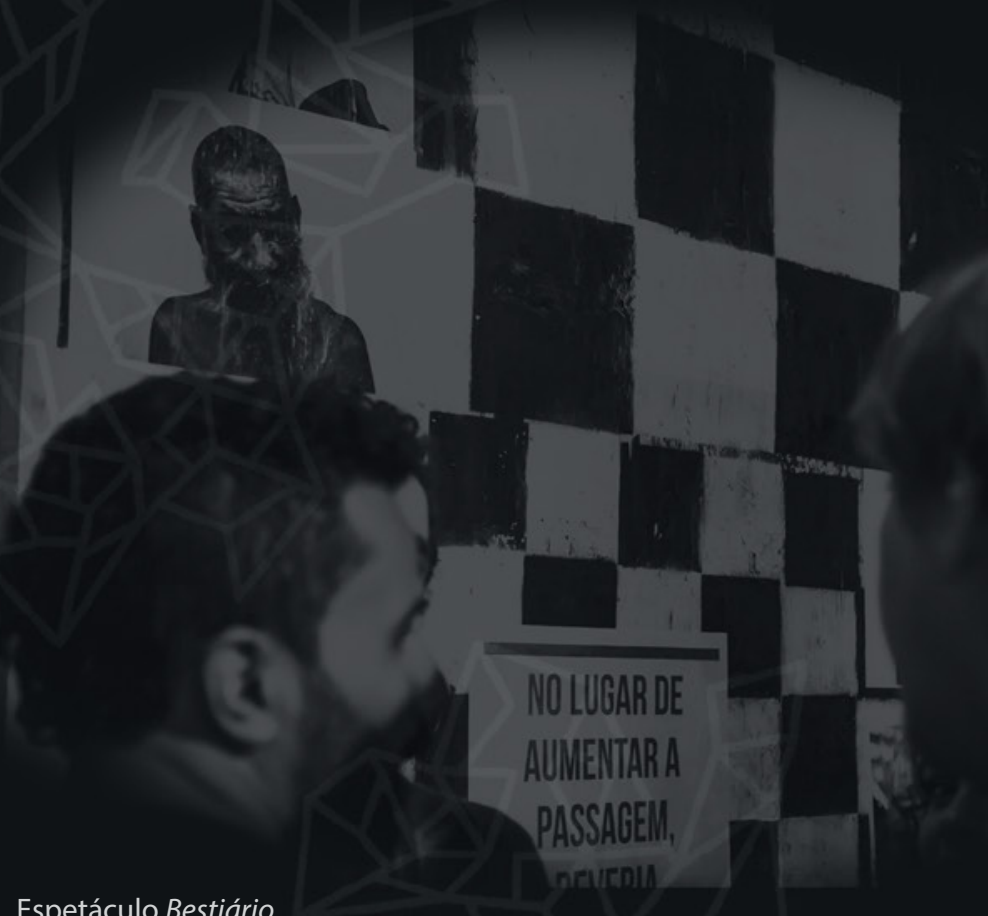

Cecília Lauritzen Jácome Campos Mestre em artes cênicas pela Universidade Federal do Rio Grande do Sul, atriz e performer do Coletivo Mapas e Hipertextos. Professora Efetiva da Licenciatura em Teatro da Universidade Regional do Cariri (URCA). 


\section{Resumo}

Este artigo problematiza o conceito de experiência e suas aproximações com a cena teatral performativa recente. Ao abordar a dinâmica da cena contemporânea, é exposto um relato da autora como espectadora do evento cênico performativo $A$ última palavra é a penúltima - 2.0 do grupo Teatro da Vertigem (SP), em que os lugares do público são revisitados sob a ótica do ato de leitura enquanto ato produtivo. A discussão traça relações entre a experiência como conceito e vivência, a estética relacional de Nicolas Bourriaud e os estudos da recepção de Flávio Desgranges, Paul Zumthor, John Dewey e Hans Ulrich Gumbrecht. A partir da noção da arte como expressão potente na alteração da percepção, questiona-se a possibilidade de falar em um 'exercício crítico da experiência'.

Palavras-chave: Experiência, Teatro performativo, Espectador, Crítica.

\section{Abstract}

The article discusses the concept of experience and its relationship with the recent performative theatrical scene. To approach the dynamics of the contemporary scene, it is presented a report of the author's experience as spectator of the performative event $A$ última palavra é a penúltima 2.0 by the group Teatro da Vertigem (São Paulo), in which public places are revisited from the perspective of the act of reading as a productive act. The discussion relates the experience as a concept with the relational aesthetics by Nicolas Bourriaud, and with reception studies by Flavio Desgranges, Paul Zumthor, John Dewey, and Hans-Ulrich Gumbrecht. From the concept of art as a potent expression in the change of perception, it is questioned the possibility of speaking in an 'experience critically exercised.' Keywords: Experience, Performative theater, Spectator, Criticism.

\section{Resumen}

Este artículo aborda el concepto de experiencia y su relación con la escena teatral reciente performativa. Al exponer la dinámica de la escena contemporánea, se presenta una narración de la autora mientras espectadora del evento performativo escénico $\mathrm{A}$ última palavra é a penúltima - 2.0 2.0 del grupo Teatro da Vertigem, en el que los lugares del público son analizados desde la perspectiva del acto de la lectura como un acto productivo. La discusión pone en escena las relaciones entre la experiencia como concepto y experiencia, la estética relacional de Nicolas Bourriaud y los estudios de recepción de Flavio Desgranges, Paul Zumthor, John Dewey y Hans Ulrich Gumbrecht. Desde el concepto del arte como una potente expresión en el cambio de percepción, se pone en duda la posibilidad de hablar en un 'ejercicio crítico de la experiencia'.

Palabras clave: Experiência, Teatro performativo, Espectador, Crítica. 


\section{A cena recente: aproximações da experiência como conceito e a estética relacional}

A concepção de "experiência", segundo as perspectivas de Walter Benjamin, mais tarde revisitada por Jorge Bondía, além dos escritos de John Dewey é adotada neste artigo como meio de aproximar o conceito do exercício da leitura no teatro. Por leitura entende-se $o$ ato do espectador, cuja condição na cena recente ultrapassa a dicotomia ativo-passivo, enquanto coprodutor da obra. Esse princípio adotado deriva do crítico literário e linguista Paul Zumthor (1997) em seu estudo sobre o papel do corpo no ato de leitura. Para o autor, a leitura se configura, ou deve ser pensada, enquanto performance, porque não só atribui sentido (em termos de decodificar uma informação) como fabrica o próprio objeto enquanto se relaciona com ele.

Ao pautar sua reflexão sobre a linguagem, Benjamin buscou ampliar o entendimento acerca da experiência, aproximando-a da essência do mundo humano. De modo mais amplo, o intuito do autor era criticar o processo de estreitamento da experiência durante a modernidade, reflexo do enfraquecimento das noções de coletividade, comunidade e sociedade. A valorização da técnica apontava para um dos paradoxos peculiares da modernidade, onde as pessoas estariam mais próximas pelo virtual e mais distantes na esfera do real, o que o autor chama de "novas patologias da época" (MEINERZ, 2008, p. 16). A partir do ensaio "O narrador" (1936), a problemática das patologias é evocada por Benjamin ao tratar da decadência da arte de narrar como expressão da pobreza da experiência. $O$ autor faz críticas ao gradual aumento de notoriedade dado às outras formas literárias, como o romance e, posteriormente, a informação jornalística. Ao excesso de informação e explicação, Benjamin opõe a erfahrung que significa "o conhecimento obtido através de uma experiência que se acumula, que se prolonga, que se desdobra, como numa viagem". (KONDER, 1988, p. 72)

Outro ponto fundamental da discussão sobre a experiência está na sua autoria. Para Bondía (2002), uma experiência não pode ser proposta, nesse processo não há agente nem paciente como antônimos naturais. A experiência acontece independente da intenção, ela é uma instância de atravessamento, de arrebatamento, nesse sentido, para que a experiência aconteça é 
preciso interrupção do agir em detrimento da exposição. $O$ autor ainda afirma que o sujeito da experiência é, sobretudo, dotado de passividade, receptividade, disponibilidade e abertura; características que vão além da oposição ativo- passivo e antecedem qualquer decisão, ou seja, representam um estado essencial de escuta.

O filósofo e pedagogo John Dewey, por sua vez, defende que toda experiência é singular, tem qualidade ímpar e, por isso, seu encerramento é uma consumação, ou seja, ela é completa em si mesma ${ }^{1}$. Ao falar da experiência estética, Dewey (2010) diz que seu caráter emocional é intrínseco e que, ao mesmo tempo, ela não pode ser efetivada sem estar com a experiência intelectual. Para o autor, a interação entre uma criatura viva e um aspecto do mundo seria um dos padrões comuns a toda experiência. Além disso, a concepção da experiência consciente se traduz na percepção de uma relação entre o fazer e o estar sujeito a algo, instâncias as quais não podem ser concebidas de forma isolada. Nesse sentido, Dewey (2010) se aproxima de Benjamin e Bondía ao postular que a ânsia de ação confere pobreza às experiências, porém se distancia em outros dois aspectos ao afirmar que a luta e o conflito são meios para desenvolver uma experiência e que o excesso de receptividade impede o amadurecimento da experiência. A esse 'excesso de receptividade' mencionado pelo autor é possível fazer aproximação com a questão da expectativa, podendo ser este um aspecto impeditivo para a experiência ao gerar precedentes no ato de leitura e percepção.

Ao discutir questões pertinentes acerca das artes contemporâneas com base nos trabalhos de Allan Kaprow e Cildo Meireles, Fervenza (2004) se aproxima da problematização aqui desenvolvida. Após transitar pelos escritos referentes ao conceito de experiência, me pergunto sobre sua possibilidade atualmente. Questiono os modos pelos quais a experiência ainda é capaz de se manifestar perante os ritmos e as dinâmicas exercidos pela sociedade atual. Nos termos da arte contemporânea, principalmente das artes cênicas ou da presença, o que pode querer dizer o termo "experiência"? Que mecanismos têm potência capaz de produzir disponibilidade para um público sempre frenético, atrasado e insatisfeito perante seus desejos? O questionamento

1. Na experiência do pensamento, por exemplo, a conclusão não é uma coisa distinta e independente; é a consumação de um movimento. (DEWEY, 2010) 
a respeito dos limites da experiência atualmente toca as práticas artísticas contemporâneas, nos casos em questão aquelas mais próximas de uma cena performativa. Essas práticas, ditas desviantes, se deslocam em busca de novas posições, fogem daquelas fixas, identificáveis. "Elas são propositivas no sentido em que não há um objeto artístico pronto para ser apreciado, mas antes um processo". (FERVENZA, 2004, p. 38)

A partir desse deslocamento (de produto para processo), a noção de público e seus lugares são redefinidos, o espectador passa a ser também criador. Entretanto, essa mudança gera efeitos que merecem atenção, porque propõe uma nova convenção da arte solicitando ao público um modo de se relacionar para além do seu território habitual. Esse deslocamento se traduz na pergunta de Desgranges (2010, p. 50): "Como compreender a pertinência de uma proposta artística que convida o espectador a disponibilizar-se para um modo de leitura que ultrapasse a barreira da dimensão lógico-racional, e se permita saborear os descaminhos da experiência com a arte?"

Retomando o princípio de Dewey (2010), no qual qualquer interação entre uma criatura viva e um aspecto do mundo pode ser considerada princípio para a experiência, faço aqui um breve adendo à discussão no intuito de questionar sobre seu caráter relacional. Para Camilletti (2010), a partir da leitura do ensaísta e crítico de arte francês Nicolas Bourriaud, a arte contemporânea e sua produção estão intrinsecamente ligadas pelas relações que estabelecem com o público, cujo raciocínio Bourriaud chama de arte relacional. Seu princípio é claro: é relacional, pois só pode se compor com o outro. Sua consequência parece, igualmente, evidente, ou seja, não me defino mais pelo que sou, mas pelas relações que tenho, podendo estender-se ao status da obra de arte que também não se define mais pelo que se intitula - teatro, dança ou performance -, mas pelas relações que consegue estabelecer com seu espectador. Para Camilletti (2010, p. 1), "o relacional implica uma instância de elaboração conjunta, na qual a decisão do espectador afete a discursividade do artista". Nesse sentido, o relacional subverte o posicionamento dual do espectador ativo-passivo colocando-o em um espaço vazio, porém de proatividade, entre as duas atitudes. Ainda sobre esse papel que o público assume, cujo sujeito não mais observa o acontecimento artístico, mas o realiza em conjunto com o artista, questiono, no intuito de desenvolver suas 
possibilidades: em que medida o espectador ainda pode assegurar seu lugar na crítica, já que o mesmo passa a ser produtor e parte integrante da obra?

\section{A cena performativa e o exercício de leitura como produção crítica}

A escolha do operador conceitual teatro performativo surge da necessidade de contemplar as diversificadas manifestações contemporâneas teatrais. A questão da performatividade se refere ao modo como uma determinada ação é feita, dessa forma, está ligada implicitamente ao como, ou seja, aos gestos e comportamentos executados pelo performer. Este foco no modo desloca a prioridade de o quê, ampliando as possibilidades de percepção da cena, extrapolando as demandas sobre a criação de sentido/significado. Segundo Féral (2008), alguns deslocamentos deixam claras determinadas características do teatro performativo, tais como: a mudança da figura do ator para o performer, a explicitação dos eventos dentro de uma ação cênica ao invés do jogo de ilusão, o espetáculo com foco na ação e na imagem, em detrimento do texto. Além desses elementos fundadores, Féral (2008, p. 198) aponta certo "apelo a uma receptividade do espectador de natureza essencialmente especular ou aos modos das percepções próprias da tecnologia”.

A oportunidade de presenciar como espectadora o espetáculo $A$ última palavra é a penúltima - 2.0 do grupo Teatro da Vertigem² (SP), bem como as reverberações desta experiência caminham na direção deste artigo. Ao ocupar a passagem subterrânea que liga o Viaduto do Chá à praça Ramos de Azevedo no centro de São Paulo e colocar os espectadores para assistir à peça dentro de pequenas cabines laterais disfarçadas de paredes (vitrines abandonadas), o espetáculo negocia certa ordem ao ambiente que vai se constituindo à medida que a encenação vai acontecendo.

As questões parecem ter se potencializado para o Teatro da Vertigem, em especial, as condições sociais e suas perspectivas de futuro. Os atores e as telas de vídeo instalados em vitrines vazias que permane-

2. Assistido em dezembro de 2014 em São Paulo durante a 31를 Bienal. Com direção de Antônio Araújo e Eliana Monteiro, inspira-se no texto de Gilles Deleuze, O esgotado. A companhia já havia montado o mesmo espetáculo em 2008 em parceria com outros dois grupos, Kikzira/MG e LOT/Peru. 
cem no local parecem lançar no visível o que a cidade tenta esconder: condições de vida, desigualdade social, interesses e o esgotamento que resulta do trabalho duro em que se envolve parte dos habitantes de São Paulo. (BIENAL DE SÃO PAULO, 2014)

O caráter performativo do espetáculo se evidencia na pele de quem o vivencia. Estar na posição de voyeur e ao mesmo tempo fora dela, recurso possibilitado pelo jogo de luzes instaurado, onde ora o espectador só enxerga o que está fora, ora vê a si mesmo enxergando, é estar em um lugar incerto. Situação que acentua o caráter relacional apontado por Camilletti (2010), porque insere o espectador nesse espaço de expectativa ampliada e constante, em uma espera entre o ver a cena e os espectadores do outro lado do corredor e o ser visto por ambos; efeito possibilitado pela estrutura das vitrines montadas nas galerias da passagem subterrânea.

A iminência do real, fruto da escolha do espaço ocupado da cidade, mas principalmente da exploração de seus fluxos naturais, deixa transparecer o vigor do trabalho e, ao mesmo tempo, sua permeabilidade. Esse caráter de troca permanente com o espaço e seu tempo revelam-se como ferramentas preciosas para quem lê, interage e produz o espetáculo, traduzindo-se como um dos mecanismos potentes dos quais se investe a cena recente para produzir certa disponibilidade no público. Em $A$ última palavra é a penúltima - 2.0 pude me aproximar das percepções sutis da cena performativa recente, seus efeitos reverberam como faíscas de um acontecimento real, permeado de traços surreais, ficcionais, bem como do campo da dúvida.

Essa experiência como espectadora, dentre outras, me leva a esmiuçar os escritos sobre o deslocamento do ato de leitura como passividade, para o ato de leitura como produção, posicionamento ativo do público. A partir dessa alteração na atitude do espectador não é apenas a relação com o espetáculo, e com a arte de modo geral, que é modificada, mas do sujeito consigo mesmo.

Desmontada a ilusão, inaugura-se um amplo campo de jogo, de vigorosa ludicidade, que não está mais apoiado no convite a que o espectador saia de si, atraído para o polo interno da obra, mas que, invadido pelo objeto artístico, vasculhe as próprias formações psíquicas e perceptivas, e, disponibilizando-se para a experiência poética, elabore outro modo de produção aurática. (DESGRANGES, 2012, p. 181-182) 
Dessa forma, a ação de contemplar a obra de arte é ampliada, de modo que, ao apreciar uma manifestação artística o espectador é convidado a olhar para si mesmo e compreender os processos pelos quais ele passa enquanto se relaciona com o objeto artístico. Nesse sentido, o caráter autoral da obra, ou a própria noção de aura, é redefinida, democratizada. Espectador e artista tornam-se coautores, como em uma relação de interdependência, na qual um não é capaz de se efetivar sem o outro. "Desde então, o espectador está convidado a se colocar como decifrador de uma obra que possui como principal objeto de análise o próprio fazer teatral, a precipitação de seu processo e a explicitação de suas perguntas." (SIMÕES, 2013, p. 194)

Zumthor (1997) investiga o papel do corpo durante o ato de leitura propondo posicionar-se no ponto de vista do leitor enquanto executa sua ação. $O$ autor deixa uma contribuição importante para essa discussão ao entender o processo de leitura como performance, ampliando-o para além da decodificação. Esse processo deve ser visto como uma ação carregada de comportamentos, posturas e estados, em que todo corpo é ativado, remexido. Percebo uma ampliação da noção de corpo, segundo Zumthor (1997), cuja compreensão permite enxergar de modo mais palpável a experiência do espectador enquanto realiza seu ato de leitura.

Diante da demanda das artes sobre esse espectador atuante, questiono acerca dos efeitos, dos afetos e processos internos de apreciação do sujeito. Ante uma sociedade espetacularizada, cujos acontecimentos são objetos de consumo para uma plateia iminente, e as emoções são esgotadas até o limite da comoção, que efeitos a arte é capaz de produzir e como o público trabalha com suas reverberações? Se ainda é possível falar sobre crítica da arte, que espécie de crítica é esta e que esfera ela contempla (individual, coletiva)? Segundo Dewey (2010, p. 134-135), há uma diferença notável entre a percepção e o reconhecimento, "no reconhecimento existe o começo de um ato de percepção", porém, ele não se completa; "o ato de percepção procede por ondas que se estendem em série por todo o organismo". Discurso ao qual pode-se acrescentar que o tempo do ato de percepção não é igualmente proporcional ao tempo do acontecimento, ou seja, as ondas de percepção também se estendem por uma duração não determinada. 
Em continuidade à investigação sobre a percepção, o estudo do teórico literário Hans Ulrich Gumbrecht (2010) acrescenta material pertinente ao discutir as noções de presença e sentido. Segundo esse teórico, a presença está associada a uma temporalidade efêmera, uma situação a qual não podemos nos agarrar, enquanto o sentido se relacionaria com o domínio da interpretação, da produção de significados. Nesse sentido, Gumbrecht (2010) acredita que a arte, assim como os esportes em alguns casos, é uma manifestação potente porque gera uma oscilação entre produção de presença (campo do tangível) e produção de sentido (campo do compreensível).

A cena performativa recente, em especial, se aproxima desse raciocínio ao estimular frequentemente as percepções dos envolvidos em um evento, utilizando como base outros disparadores além do texto dramático e sua interpretação fiel. Tomando como princípio a 'oscilação' de que fala Gumbrecht, penso que a relação presença-sentido se dá de forma simultânea, como afirma Dewey (2010, p. 130): "em uma enfática experiência artístico-estética, a relação é tão estreita que controla ao mesmo tempo o fazer e a percepção". Durante a operação complexa de 'oscilação', em que a percepção se inicia e continua repercutindo no sujeito, quando se dá o exercício crítico e de que maneiras ele se manifesta? Que parâmetros ainda temos para exercer a crítica sobre a arte? Se a cena performativa permite esse exercício, de que maneira concretizá-lo para além do discurso?

Dewey (2010) discute as noções de crítica e percepção apontando duas escolas de pensamento emblemáticas representadas pelos críticos judicativos e os impressionistas. Os primeiros advêm da crítica como atividade do juízo, ligada à figura do juiz, ou seja, àquele que ocupa um lugar de autoridade social. Os impressionistas, por sua vez, surgiram em reação à crítica judicativa. Essa escola defende a atividade crítica como uma "afirmação das reações de sentimento e imagens provocadas pelo objeto artístico" (DEWEY, 2010, p. 518) e, nesse caso, o autor concentra sua discussão em torno do campo das artes visuais. O perigo, alerta Dewey (2010), está na falta de objetividade que esse exercício proporciona, conduzindo o incentivo à impressão como a expressão de opiniões pouco refletidas ou fundamentadas. Para o autor, é preciso definir uma impressão, ao invés de, simplesmente, enunciá-la. "Mas definir uma impressão é analisá-la, e a análise só pode prosseguir indo além 
da impressão, referindo-a às bases em que ela se apoia e às consequências que acarreta. E esse procedimento é o juízo". (Ibid., p. 519)

Entre a extrema objetividade dos judicativos e a negação de qualquer tipo de critério dos impressionistas, Dewey (2010) defende a visão da crítica como um exercício que se baseia em critérios de julgamento pautados na concepção da arte como experiência. A partir da concepção de experiência, podem-se retomar as premissas da arte contemporânea nas quais as questões sobre o efeito estão mais concentradas a respeito do que acontece com cada um, ao invés de uma interpretação exata sobre o que acontece no espaço da cena. Para Dewey (2010, p. 548), "a função da crítica é reeducar a percepção das obras de arte; ela é um auxiliar no processo de aprender a ver e a ouvir". Nesse sentido, o valor da experiência crítica se desloca da pura objetividade ou produção de sentido para sua capacidade em revelar a multiplicidade de ideais que a obra tem em si. Retomo a fala de Zumthor (1997, p. 38), em que defende a consideração do corpo no estudo do ato de leitura (entendido por ele como performance): "ora, o corpo (que existe enquanto relação, a cada momento recriado, do eu ao seu ser físico) é da ordem do indizivelmente pessoal". O 'indizivelmente pessoal' reforçado pelo autor me faz retomar uma questão anteriormente colocada: se ainda é possível falar sobre crítica da arte, visão que defendo, que espécie de crítica é esta e que âmbito ela contempla (individual, coletivo)?

Tomo como premissa a lógica de pensamento da estética da recepção, na qual existe uma relação de tensão entre o estético (forma) e o histórico (conteúdo) que não é excludente. Segundo Desgranges (2012, p. 22), pensar sobre o que a arte produz é, igualmente, um exercício de refletir acerca das alterações na percepção, em outras palavras, "por um lado, as modificações no contexto social solicitam soluções artísticas renovadas [...] por outro lado, o fazer artístico também participa e influencia essas alterações na perceptividade". Estendo a lógica desse raciocínio às questões relativas ao juízo, ou à produção de conhecimento crítico/reflexivo sobre a arte. Desse ponto de vista, a ordem do 'indizivelmente pessoal' ou íntimo não se manifesta como um elemento redutor, limitador nem inviabilizador da questão da crítica, senão como um pensamento que impulsiona a investigação acerca da recepção da cena performativa recente. 


\section{Referências bibliográficas}

BIENAL DE SÃO PAULO. A última palavra é a penúltima - 2.0. 2014. Disponível em: <http://www.bienal.org.br/post.php?i=1705>. Acesso em: 20 jan. 2015.

BONDÍA, J. L. Notas sobre a experiência e o saber de experiência. Revista Brasileira de Educação, Campinas, v. 19, p. 20-28, abr. 2002.

CAMILLETTI, G. La dimensión política de lo relacional. Territorio Teatral, Buenos Aires, 2010. Disponível em: <http://territorioteatral.org.ar/html.2/dossier/n6_01. html>. Acesso em: 13 jan. 2015.

DESGRANGES, F. Arte como experiência da arte. Lamparina: Revista de ensino de teatro, Belo Horizonte, v. 1, n. 1, p.50-56, jun. 2010.

A inversão da olhadela: alterações no ato do espectador teatral. São Paulo: Hucitec, 2012, 228 p.

DEWEY, J. Crítica e percepção. In: Arte como experiência. Trad. Vera Ribeiro. São Paulo: Martins Fontes, 2010. 646 p.

FÉRAL, J. Por uma poética da performatividade: o teatro performativo. Trad. Lígia Borges. Revista Sala Preta, São Paulo, n. 8, p. 197-210, 2008.

FERVENZA, $H$. Considerações da arte que não se parece com arte. Letras, $n$. 28/29, p. 131-139, 2004.

GUMBRECHT, H. U. Produção de presença: o que o sentido não consegue transmitir. Trad. Ana Isabel Soares. Rio de Janeiro: Contraponto, 2010.

KONDER, L. Walter Benjamin: o marxismo da melancolia. Rio de Janeiro: Campus, 1988. $112 \mathrm{p}$.

MEINERZ, A. Concepção de experiência em Walter Benjamin. 2008. Dissertação (Mestrado) - Universidade Federal do Rio Grande do Sul, Porto Alegre, 2008.

SIMÕES, G. O espectador em pleno voo: as experiências do iNERTE. Revista Sala Preta, São Paulo, v. 13, n. 2, p. 193-199, 2013.

ZUMTHOR, P. Introdução à poesia oral. Trad. Jerusa Pires Ferreira, Maria Lúcia Diniz Pochat e Maria Inês de Almeida. São Paulo: Hucitec, 1997.

Recebido em 27/03/2016

Aprovado em 20/05/2016

Publicado em 30/06/2016 